\title{
Role of estrogen in induction of penile dysmorphogenesis: a review
}

\author{
$\mathrm{H} \mathrm{O} \mathrm{Goyal}^{1}$, T D Braden ${ }^{3}, \mathrm{C} \mathrm{S} \mathrm{Williams}^{1}$ and J W Williams ${ }^{2}$ \\ ${ }^{1}$ Department of Biomedical Sciences, College of Veterinary Medicine, Nursing and Allied Health and ${ }^{2}$ Department of \\ Biology and CBR/RCMI, Tuskegee University, Tuskegee, Alabama 36088, USA and ${ }^{3}$ Department of Physiology and \\ Pharmacology, Auburn University, Auburn, Alabama, USA
}

Correspondence should be addressed to H O Goyal; Email: goyalho@tuskegee.edu

\begin{abstract}
In this review, we report permanent dysmorphogenesis of the penis and loss of fertility in adult rats treated neonatally with estrogen. Specifically, we report replacement of smooth muscle cells and cavernous spaces by fat cells in the corpus cavernosum penis, but not in the adjoining corpus spongiosum. Induction of these novel, region-specific phenotypes is dose-dependent, requires a critical window of exposure and associated with decreased testosterone and up-regulation of estrogen receptor $\alpha(E R \alpha)$. The resistance of ER $\alpha$ knockout mice to develop these abnormalities implies an unequivocal role for ER $\alpha$ in mediating maldevelopment of the penis. Additionally, the prevention of estrogen-inducible penile abnormalities by ER antagonist ICI $182780 \mathrm{implies}$ that a functional ER-mediated pathway is essential for inducing penile abnormalities. Likewise, the ability of testosterone or dihydrotestosterone to negate these abnormalities suggests a role for an androgen receptor (AR)-mediated pathway. Taken together, these observations led us to hypothesize that neonatal estrogen exposure, via an ER-mediated pathway (direct action) or an AR-mediated pathway (indirect action through decreased testosterone) or both pathways, up-regulates ER $\alpha$ expression in stromal cells of the penis, which are then reprogrammed such that their differentiation into smooth muscle cells is inhibited and their differentiation into adipocytes is stimulated.
\end{abstract}

Reproduction (2007) 134 199-208

\section{Introduction}

The role of androgens in development of male reproductive organs is well documented in all mammals (George \& Wilson 1994). While testosterone is essential in development of organs derived from the mesonephric duct, including the epididymis, ductus deferens, and seminal vesicles; dihydrotestosterone (DHT), a 5- $\alpha$ reduced testosterone metabolite, is critical in development of organs derived from the urogenital sinus, genital tubercle, and genital swelling, including the scrotum, prostate, and penis (Anderson \& Clark 1990, George \& Wilson 1994, Wilson \& Davies 2007). Alterations in androgenic activity during differentiation can cause maldevelopment of internal and external male genitalia, including hypospadias and shorter penis (Gray et al. 2001, Sultan et al. 2001, Kim et al. 2002, Foster \& Harris 2005).

However, unlike androgens, the role of estrogen in development of male reproductive organs, especially in the penis, remains largely unknown; although both estrogen receptors (ERs) and/or aromatase enzyme have been identified in the developing penis of a number of species, including humans (Crescioli et al. 2003, Schultheiss et al. 2003, Dietrich et al. 2004), rodents (Jesmin et al. 2002, 2004), and rabbits (Srilatha \& Adaikan 2004). Epidemiological studies have shown links between inappropriate estrogen exposure and higher frequency of reproductive abnormalities in men and wild animals (Toppari et al. 1996, McLachlan et al. 2001, Safe et al. 2001, Mosconi et al. 2002, Fisher 2004, Vidaeff \& Sever 2005, Storgaard et al. 2006, reviews). Male offspring of women exposed to diethylstilbestrol (DES) during pregnancy have higher incidence of epididymal cysts, cryptorchidism, hypospadias, and smaller penis (Gill et al. 1979, Swan 2000, Klip et al. 2002). Laboratory animals exposed neonatally to estrogen develop hypospadias (McLachlan et al. 1975, Kim et al. 2004, Newbold 2004). Neonatal exposure to estrogen at low doses enlarges the prostate gland, while higher doses have the opposite effect (vom Saal et al. 1997, Gupta 2000, Putz et al. 2001, vom Saal \& Hughes 2005). Taken together, the above studies suggest that prenatal and/or neonatal exposure to estrogens can have permanent deleterious effects on the development of male reproductive organs; however, the mechanism underlying estrogen-inducible 
abnormal phenotypes in the male reproductive tract, as well as in the penis, remains unknown.

Recently, we reported permanent dysmorphogenesis of the penis and loss of fertility in adult rats treated neonatally with DES or EV (Goyal et al. 2004a, 2004b, 2005a, 2005b). Importantly, these studies showed replacement of smooth muscle cells and cavernous spaces by fat cells in the corpora cavernosa penis. Additionally, these effects were dose dependent, required a critical window of exposure, and were associated with decreased plasma testosterone and up-regulation of ER $\alpha$ expression in the body of the penis. The objective of this review is to present the above data in a comprehensive manner and discuss the mechanism by which neonatal exposure to estrogen stimulates adipogenesis and inhibits smooth muscle cell differentiation during a critical period of penile development.

Hence, in this review, we will first present a brief description of the rat penis morphology at the gross and histological levels for the purpose of orientation. This will be followed by data that neonatal estrogen exposure results in permanent penile dysmorphogenesis characterized by replacement of cavernous spaces and smooth muscle cells by fat cells in the body of the penis (Goyal et al. 2004a); estrogen-induced penile disorders are dose-dependent (Goyal et al. 2005a), as well as are dependent upon estrogen exposure during a critical period of penile development (Goyal et al. 2005b); neonatal estrogen exposure results in up-regulation of $E R \alpha$, but without any alteration in $E R \beta$ or androgen receptor (AR) expression, in the body of the penis (Goyal et al. 2004b); ER $\alpha$ knockout (ER $\alpha K O)$ mice are resistant to estrogen-inducible penile abnormalities (Goyal et al. 2007); neonatal estrogen exposure lowers testosterone secretion at puberty or adulthood (Goyal et al. 2004b) and suppresses neonatal testosterone surge (Goyal et al. 2005b); and the coadministration of ER antagonist or androgen with estrogen mitigates estrogen-inducible developmental penile abnormalities. Finally, we will discuss possible mechanisms by which neonatal estrogen exposure results in penile dysmorphogenesis.

\section{Morphology of the rat penis}

Grossly, the adult penis in control rats consists of a cylindrical body, a bulbous glans penis, a right angle between the body and the glans, and an os penis that extends from distal end of the body to tip of the glans and consists of proximal and distal parts (Fig. 1A). Microscopically, the body consists of a pair of corpora cavernosa, which are located dorsolateral to the urethra and are partially separated by a septum bringing blood vessels and nerves to the penis, and a corpus spongiosus that surrounds the urethra (Fig. 1B). The corpora cavernosa are surrounded by a thick connective tissue capsule called tunica albuginea, which consists of an inner cellular layer and an outer fibrous layer, and contain endothelial-lined cavernous spaces (also called sinusoids or lacunae), smooth
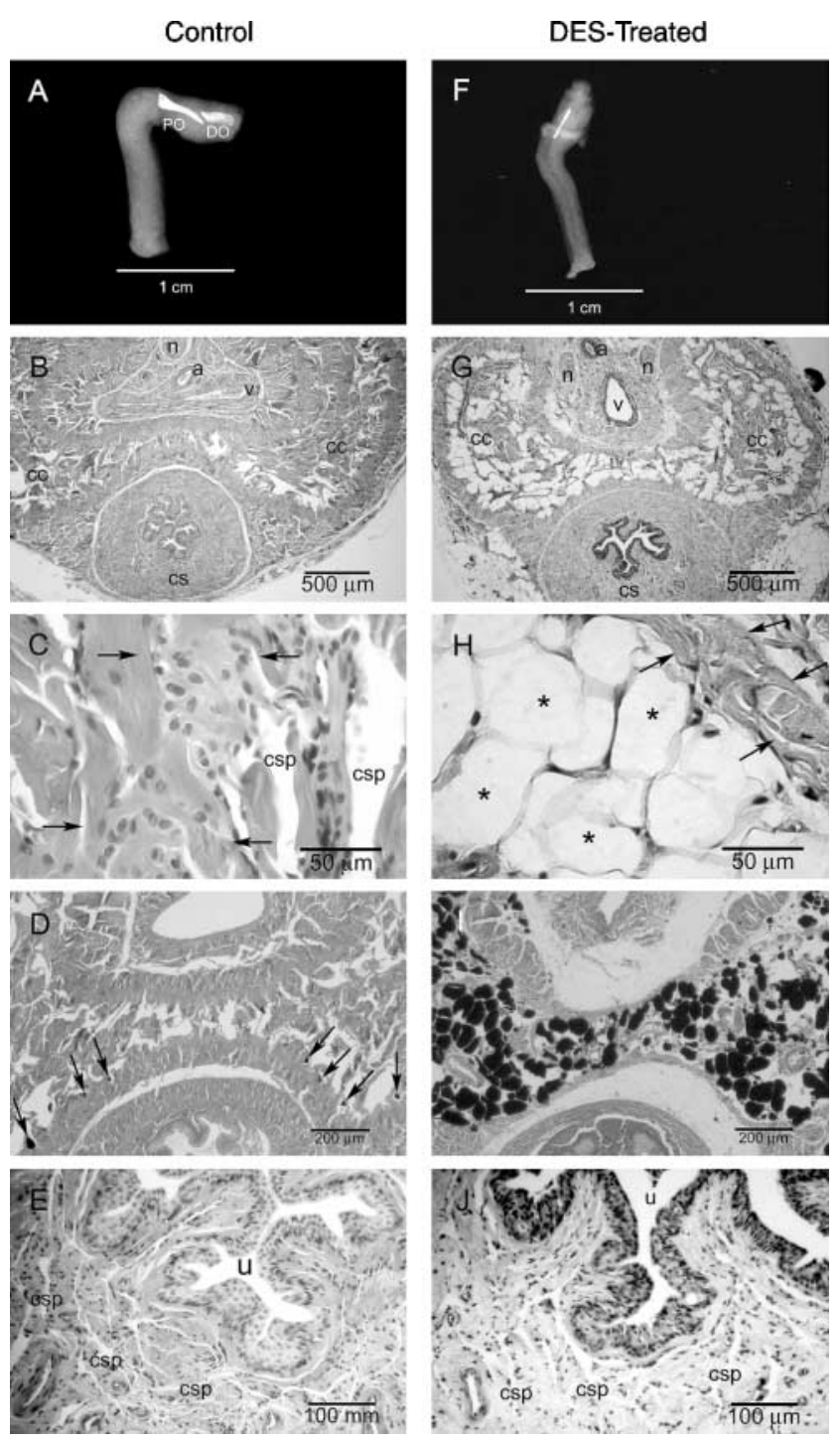

Figure $1(\mathrm{~A}-\mathrm{J})$ Micrographs of the penis in adult rats treated neonatally with oil (control, A-E) or DES (F-J). (A and F) Radiographs of the penis showing a cylindrical body and a bulbous glans penis containing an os penis consisting of proximal (PO) and distal (DO) parts. Note a reduction in the angle between the body and glans of the penis and maldevelopment of the os penis, as a result of DES treatment. (B and G) Although different parts of the body of the penis, paired corpora cavernosa penis (cc), corpus spongiosus (Cs), and septum containing vein ( $\mathrm{v}$ ) artery (a) and nerve bundles ( $\mathrm{n}$ ) are similarly organized between the control and treated rats; the corpora cavernosa in the treated rats are markedly reduced in thickness and contain wider spaces and fewer fibers. ( $\mathrm{C}$ and $\mathrm{H}$ ) Note a thick, cellular tunica albuginea (arrows), and cavernous spaces (csp) in the corpus cavernosum of the control rat, in contrast to empty appearing fat cells (asterisks) and a thinner and much less cellular tunica albuginea (arrows) in the treated rat. (D and I) Note aggregation of black staining fat cells in the corpora cavernosa of the treated rat, in contrast to isolated, small fat droplets in the control rat (arrows). (E and J) Note similarities in the histological structure of the corpus spongiosum in the control and treated rats; csp, cavernous spaces; u, urethra. (B, C, E, G, H and J), Hematoxylin and eosin; ( $D$ and I), fat stain. A and F, reproduced with permission, Goyal et al. 2005 Biology of Reproduction 70 1504-1512. B-E and G-J, reproduced with permission, Goyal et al. 2004 Reproductive Toxicology 18 265-274. 
muscle cells, and collagen fibers (Fig. 1C). Additionally, they also contain a few fat cells that are more clearly identified in paraffin sections stained with osmium tetroxide (Fig. 1D). The corpus spongiosus is structurally similar to the corpora cavernosa, but cavernous spaces and smooth muscle cells are less developed (Fig. 1E).

\section{Neonatal exposure to estrogen induces permanent penile dysmorphogenesis}

Neonatal male rats received, s.c., $25 \mu$ olive oil containing DES at a dose of $10 \mu \mathrm{g}$ per rat $(1 \mathrm{mg} / \mathrm{kg})$ per day, on alternate days from postnatal days 2-12. Controls received oil only. Fertility was tested at 150 days and tissues were examined at 200 days. The penis in DES-treated rats was grossly malformed (Fig. 1F), the os penis was under-developed and the thickness of the corpora cavernosa, but not that of the corpus spongiosus, was dramatically reduced (Fig. 1G). The cavernous spaces and smooth muscle cells in the corpora cavernosa were replaced by empty appearing cells, which were confirmed as adipocytes in paraffin sections stained with osmium tetroxide (Fig. $1 \mathrm{H}$ and I). Conversely, the morphology of the corpus spongiosus was unaltered, as a result of DES treatment (Fig. 1J). While all females mated with control males $(n=7)$ had $3-5$ copulatory plugs each and delivered pups (fertility index: 100\%), none of the females mated with treated males $(n=14)$ had pups (fertility index: $0 \%$ ) and only one female had a small copulatory plug. In conclusion, adult rats treated neonatally with estrogen develop permanent dysmorphogenesis of the penis and loss of fertility, which probably results from erectile dysfunction as indicated by treated males' inability to deposit vaginal plugs.

\section{Penile dysmorphogenesis is dose- and time- dependent}

\section{Dose of exposure}

Male pups received DES or EV at a dose of $10 \mu \mathrm{g}$ $(1 \mathrm{mg} / \mathrm{kg}), 1 \mu \mathrm{g}, 100 \mathrm{ng}, 10 \mathrm{ng}$, or $1 \mathrm{ng}$ per rat on alternate days from postnatal days $2-12$. Fertility was tested at 120 days and tissues were examined at 150 days. Generally, DES and EV induced similar effects within the $10 \mu \mathrm{g}$ and the $1 \mu \mathrm{g}$ groups. Fertility was reduced to zero; the os penis was malformed (not shown because effects were similar to those shown in Fig. 1F); the weight and length of the penis were decreased in a dose-dependent manner (Fig. 2A); and smooth muscle cells and cavernous spaces were replaced by adipocytes (not shown because effects were similar to those shown in Fig. $1 \mathrm{H}$ and I). Conversely, penile morphology and fertility were similar to controls in the lower dose groups, except four out of seven males in the $100 \mathrm{ng}$ DES group, which did not sire pups. The loss of fertility in all these four males was associated with penile abnormalities similar to those observed in the higher dose groups. In conclusion, neonatal exposure to DES or EV at a dose of $1 \mu \mathrm{g}(0.1 \mathrm{mg} / \mathrm{kg})$ or higher per day on alternate days from postnatal days 2-12 results in abnormal development of the penis and loss of fertility in $100 \%$ of the treated rats, although a lower dose $(0.01 \mathrm{mg} / \mathrm{kg})$ also causes infertility, but at a reduced percentage.

\section{Time of exposure}

Male pups received EV at a dose of $1 \mu \mathrm{g}$ per pup $(0.1 \mathrm{mg} / \mathrm{kg}$, the dose that results in $100 \%$ infertility in the dose-dependent study), each day on postnatal day (s) 1 , $1-3,4-6,1-6,7-12,13-18,19-24$, or 25-30 (dose was adjusted based upon pup's weight). DES was not included because DES and EV had similar effects in the dosedependent study. Fertility was tested at 120 days and tissues were examined at 140-150 days of age. Both fertility and penile morphology were unaltered in rats treated after 12 days of age. Conversely, except in rats treated on postnatal day 1 only, none of the males treated prior to postnatal day 12 sired pups and all had abnormal penises, including reductions in the length and weight of the penis (Fig. 2B) and varying degrees of abnormal accumulation of adipocytes, which was maximal in the 1-6-day group (Fig. 2C). In conclusion, estrogen exposure prior to 12 days of age, as short as 1-3 postnatal days, results in permanent penile deformities and loss of fertility.

\section{Penile dysmorphogenesis is associated with ER $\alpha$ up-regulation}

Male pups received DES at a dose of $10 \mu \mathrm{g}(1 \mathrm{mg} / \mathrm{kg})$ per rat on alternate days from postnatal days $2-12$. Tissue samples were collected at days 18 (prepuberty), 41 (puberty), and 120 (adulthood) of age and examined for $E R \alpha, E R \beta$, and $A R$ expression in the body of the penis. AR-positive cells were ubiquitous and their profile (incidence and staining intensity) did not differ between controls and treated rats in any age group (Fig. 3A and B). Conversely, ER $\alpha$-positive cells (mostly stromal), while few and faintly stained in controls, were abundant and intensely stained in all age groups of treated rats, especially at 18 days (Fig. 3C and D). RT-PCR confirmed immunocytochemical data where ER $\alpha$ expression was enhanced and AR expression was unaltered, as a result of neonatal DES exposure (Fig. 3E). Unlike $E R \alpha, E R \beta$ expression was high in both control and treated groups (Fig. 3F). In conclusion, neonatal estrogen exposure results in $E R \alpha$ up-regulation, but without an alteration in expression for $E R \beta$ or $A R$.

\section{$E R \propto$ presence is essential in estrogen-inducible penile dysmorphogenesis}

The heterozygous breeding pairs for the ER $\alpha$ null allele were crossed to generate $\mathrm{ER} \alpha \mathrm{KO}$ and wild-type $\mathrm{C} 57 \mathrm{BL} / 6$ 
mice in a continuous breeding scheme at the University of Illinois, Champaign/Urbana. Pups were treated with DES at a dose of $200 \mathrm{ng}(0.1 \mathrm{mg} / \mathrm{kg}$ same as in the rat $)$ in $25 \mu \mathrm{l}$ olive oil, per pup, every other day, from postnatal

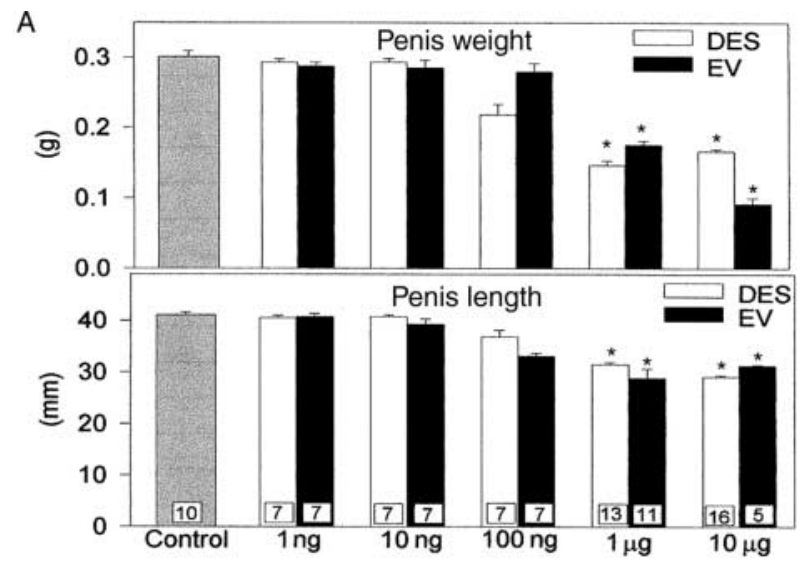

B

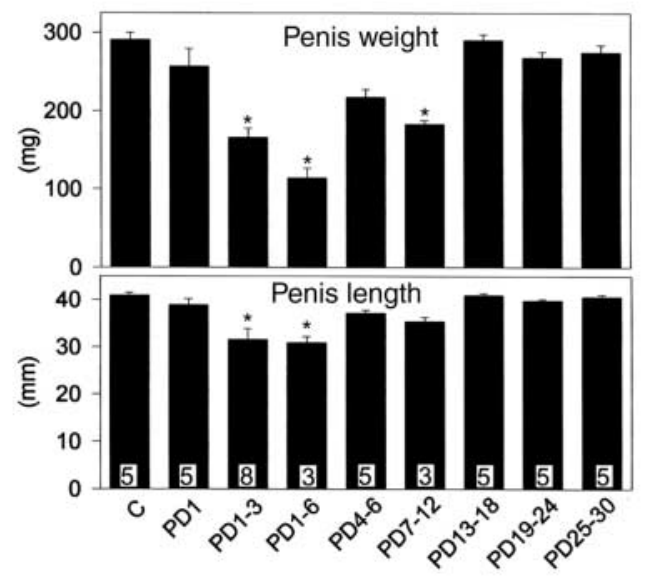

C
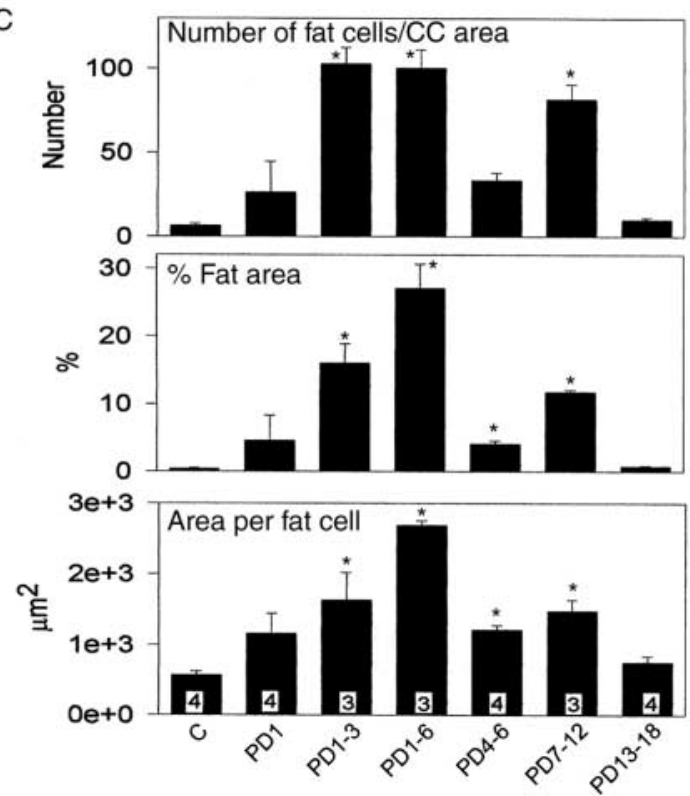

Postnatal Day(s) (PD) days 2-12. Controls received oil only. Between 8 and 12 days of age, DNA was isolated from tail tissues using Direct PCR Lysis Reagent (Viagen Biotech Inc., Los Angeles, CA, USA) and used to determine genotype. Animals were shipped to Tuskegee University at adulthood for further study. Fertility was tested at 90-120 days of age ( $n=5-7$ each group) and tissues were collected at 96-153 days of age.

Penises from the wild-type treated mice only showed abnormalities, which were similar to those observed in the rat penis, including maldevelopment of the os penis (Fig. 3G) and reductions in the length and weight of the penis (Fig. $3 \mathrm{H}$ ). While all wild-type control males sired pups, none did in the wild-type treated or knockout control or knockout treated males. In conclusion, the $\alpha$ ERKO mice are resistant to estrogen-inducible penile abnormalities present in the wild-type littermates implying an unequivocal role for $E R \alpha$ in mediating maldevelopment of the penis.

\section{Penile dysmorphogenesis is associated with lower plasma and intra-testicular testosterone}

\section{Plasma testosterone}

Effect of the age of the animal

Male pups received DES at a dose of $10 \mu \mathrm{g}(1 \mathrm{mg} / \mathrm{kg})$ per rat on alternate days from postnatal days $2-12$. Plasma samples were collected at days 18 (prepuberty), 41 (puberty), and 120 (adulthood) and were frozen at $-20^{\circ} \mathrm{C}$ until assayed. The mean plasma testosterone concentration was negligible at all age groups in treated animals, whereas it increased from a negligible level at day 18 to $1.0 \mathrm{ng} / \mathrm{ml}$ at day 41 to $1.50 \mathrm{ng} / \mathrm{ml}$ at day 120 (Fig. 4A).

\section{Effect of the dose of estrogen exposure}

Male pups received DES or EV at a dose of $10 \mu \mathrm{g}, 1 \mu \mathrm{g}$, $100 \mathrm{ng}, 10 \mathrm{ng}$, or $1 \mathrm{ng}$ per rat on alternate days from postnatal days 2-12. Plasma samples were assayed at 150 days of age. While the mean concentration of plasma testosterone in the 1 or $10 \mathrm{ng}$ DES and EV groups was not significantly $(P \leq 0.05)$ different from that of controls $(2.78 \mathrm{ng} / \mathrm{ml})$, it was significantly reduced in the $100 \mathrm{ng}$ and higher dose DES and EV groups (Fig. 4B).

Figure $2(A-C)$ In these graphs, note effects of neonatal DES or estradiol valerate (EV) exposure for various doses on the weight and length of the penis at adulthood (A); effects of neonatal EV exposure for various postnatal days of age on the weight and length of the penis at adulthood (B); and effects of neonatal EV exposure for various postnatal days of age on numbers of fat cells in a unit area, percent area occupied by fat cells in a unit area, and area of fat cells in the corpora cavernosa $(C)$ in rats at adulthood. Data are expressed as mean \pm s.E.M. ${ }^{*}(P<0.05)$. A, reproduced with permission, Goyal et al. 2005 Journal of Andrology 26 32-43. B and C, reproduced with permission, Goyal et al. 2005 Toxicological Sciences 87 242-254. 

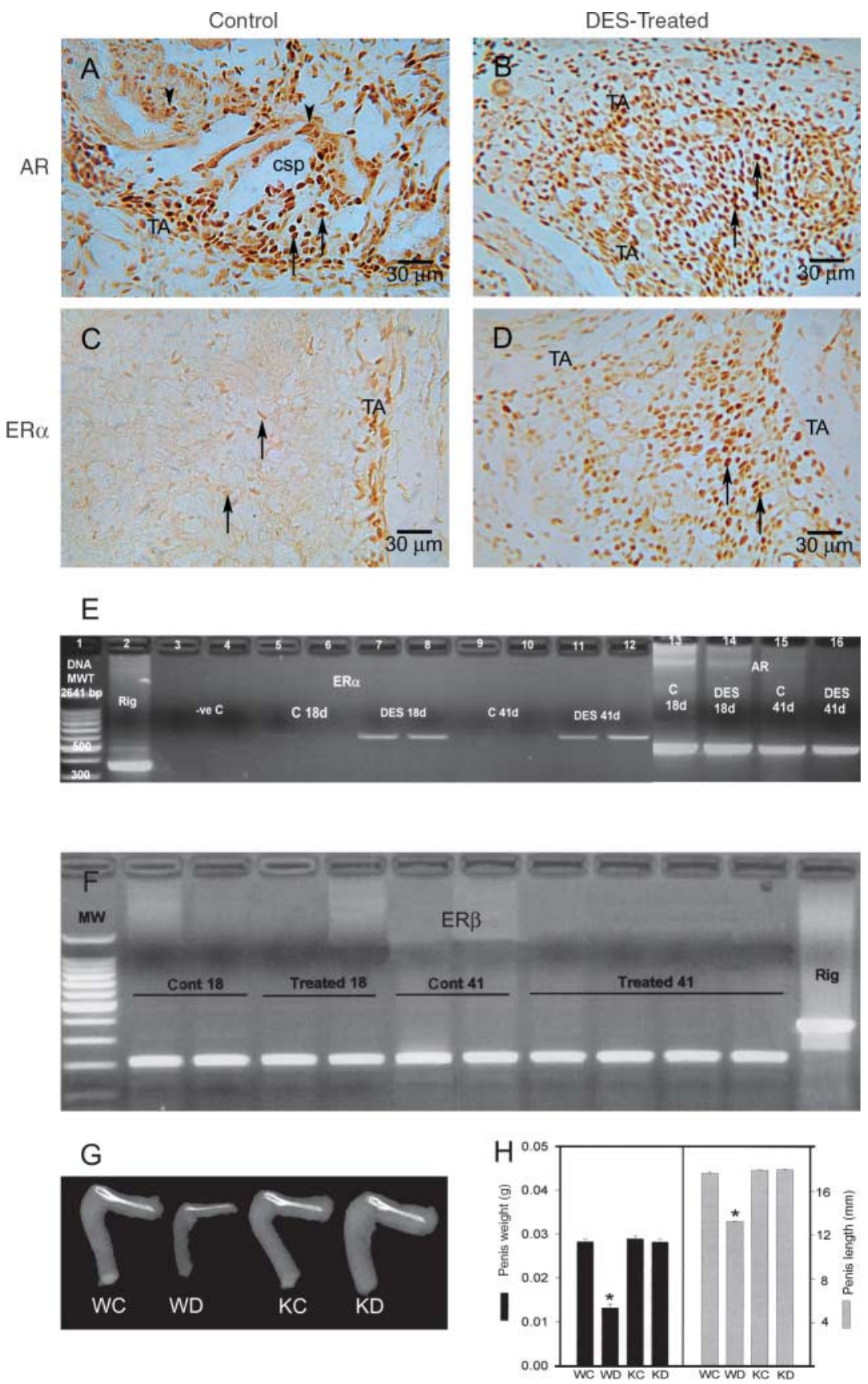

Figure $3(A-D)$ Immunolocalization of androgen receptor (AR) (A and B) and estrogen receptor (ER) $\alpha(C$ and $D)$ in the corpus cavernosum penis at 18 days of age in rats treated neonatally with oil (control, $A$ and $C$ ) or DES (B and D). Note similarities in staining intensity and incidence of AR-positive cells in the control (A) and treated rats (B). Conversely, note a marked increase in the expression of ER $\alpha$-positive cells in the treated rat (compare $\mathrm{C}$ with D). Similar results were found at 41 days of age and thus are not shown. Cavernous spaces (csp); smooth muscle cells (arrowheads); fibroblast-like cells (arrows); and tunica albuginea (TA). A-D, reproduced with permission, Goyal et al. 2005 Biology of Reproduction 70 15041512. (E) Expression of ER $\alpha$ and AR mRNAs in the body of the penis at 18 and 41 days of age in control (c) rats and in rats treated neonatally with DES. Lane 1, DNA molecular weight markers; lane 2, house-keeping gene; lanes 3 and 4, negative controls; lanes 5-12, ER $\alpha$; lanes 13-16, AR. Note marked up-regulation of ER $\alpha$ at both 18 and 41 days of age, as a result of DES treatment. (F) Expression of ER $\beta$ mRNA in the body of the penis at 18 and 41 days of age in control rats and in rats treated neonatally with DES. Note similar expression in both control and treated groups. (G) Radiographs of the penis in wild-type control (WC), wild-type DES (WD), ER knockout control (KC), and ER knockout DES (KD) adult mice treated neonatally with oil (control) or DES. Note abnormal morphology of the penis, including maldevelopment of the os penis, in DES-treated wild-type mice only. Reproduced with permission, Goyal et al. 2007 Reproduction 133 1057-1067. (H) The length and weight of the penis in wild-type control (WC), wild-type DES (WD), ER $\alpha$ knockout control (KC), and ER $\alpha$ knockout DES (KD) adult mice treated neonatally with oil (control) or DES. Again, note only the wild-type treated (WD) mice showed significant reductions. Data are expressed as mean \pm S.E.M. $*(P<0.05)$. 
A

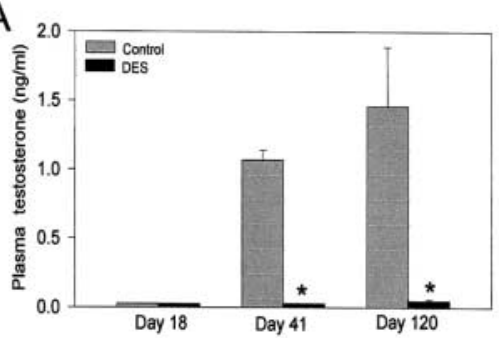

C

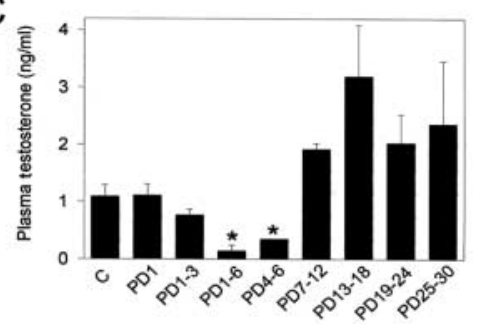

B

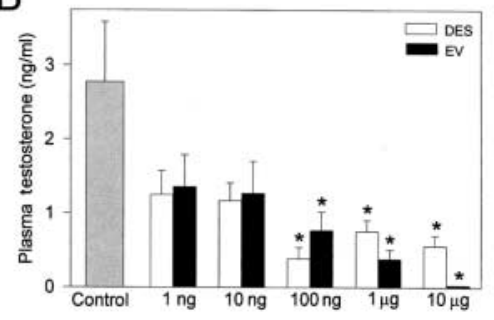

$\mathrm{D}$

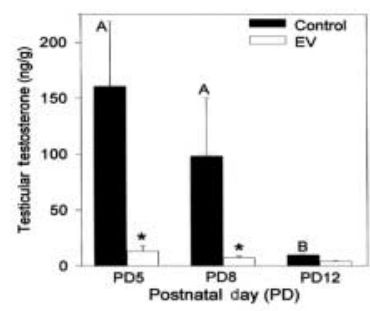

E
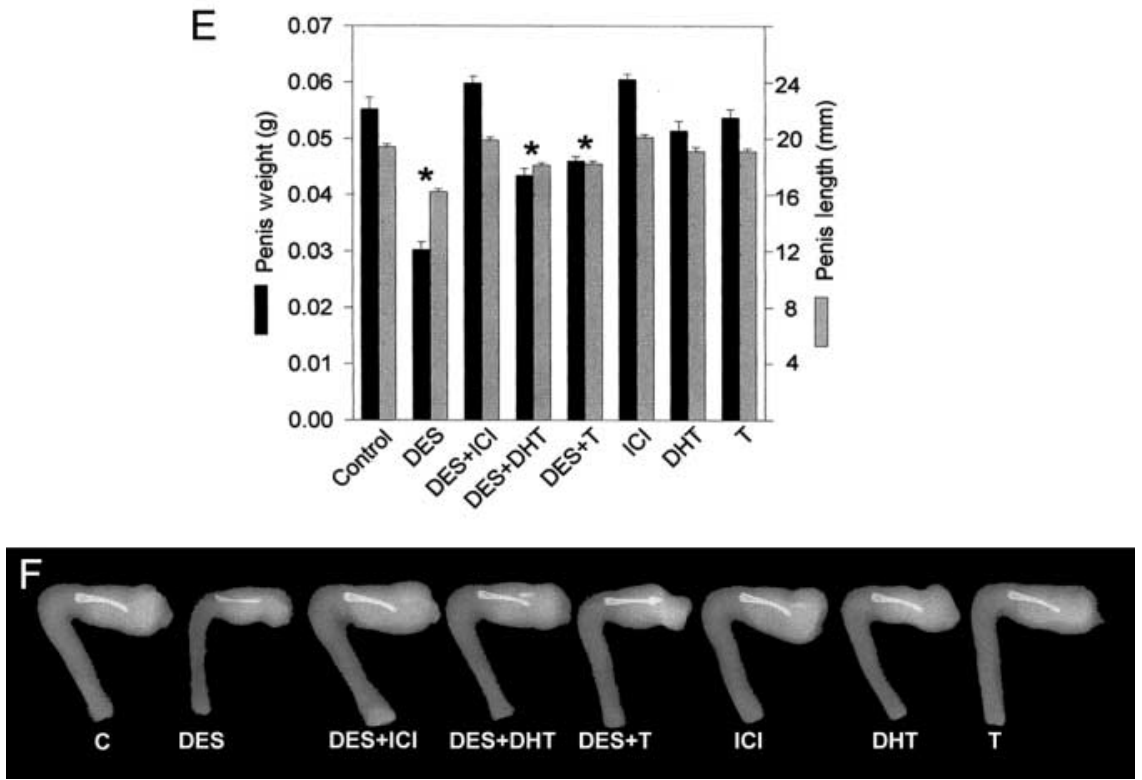

Figure 4 (A-D) Effect of neonatal DES exposure on plasma testosterone at prepuberty (18 days), puberty (41 days), and adulthood (120 days) (A); effect of neonatal DES or estradiol valerate (EV) exposure for various doses on plasma testosterone at adulthood (B); effect of neonatal EV exposure for various postnatal days of age on plasma testosterone at adulthood (C); and effect of neonatal EV exposure for postnatal days 1-3 on intra-testicular testosterone concentration in rats at postnatal day 5, 8, and 12. Data are expressed as mean \pm s.E.M. * $(P<0.05)$. A, reproduced with permission, Goyal et al. 2005 Biology of Reproduction 70 1504-1512. B, reproduced with permission, Goyal et al. 2005 Journal of Andrology 26 32-43. C and D, reproduced with permission, Goyal et al. 2005 Toxicological Sciences 87 242-254. (E) Effect of neonatal DES exposure, with or without coadministration of ICI 182780 or DHT or testosterone $(\mathrm{T})$, on the weight and length of penis at 28 days of age. Note that ICI, DHT, and T coadministration with DES reverses DES-induced reductions in both length and weight of the penis, although the level of reversal was somewhat lower in the case of DHT and T. Data are expressed as mean \pm S.E.M. $*(P<0.05)$. (F) Radiographs of the penis in the 28-day-old rats treated neonatally with oil $(\mathrm{C})$, or DES, or DES + ICl, or DES + DHT, or $\mathrm{DES}+\mathrm{T}$, or ICl, or DHT, or T. Note that ICl, DHT, and T coadministration mitigates DES-induced mal-development of the os penis.

\section{Effect of the time and length of estrogen exposure}

Male pups received $\mathrm{EV}$ at a dose of $1 \mu \mathrm{g}$ per pup, each day on postnatal day (s) $1,1-3,4-6,1-6,7-12,13-18$, 19-24, or 25-30. Plasma samples were assayed at 140-150 days of age. The mean plasma testosterone concentration was significantly lower in the $1-6$ and 4-6 day groups only (Fig. 4C).

\section{Intra-testicular testosterone}

The intra-testicular testosterone concentration was determined in rats treated with EV at a dose of $1 \mu \mathrm{g}$ per pup, each day on 1-3 postnatal days. Testes were collected and frozen on postnatal days 5, 8 , and 12 . The rationale was to find out whether estrogen treatment results in suppressing the neonatal intra-testicular 
testosterone surge that is typical for rodents from late gestation (18.5-19.5 days) to the first week of life (Ward \& Weisz 1984, El-Gehani et al. 1998). The reason for treating pups for 1-3 postnatal days was that, among various treatment groups, this was the earliest and the shortest developmental period in which estrogen exposure resulted in abnormal penis and loss of fertility (see above section C, Time of Exposure).

The mean intra-testicular testosterone concentration in control rats at 5 and 8 days of age was 160 and $98 \mathrm{ng} / \mathrm{g}$ respectively as opposed to $<10 \%$ of the control values in the treated rats (Fig. 4D), implying that neonatal estrogen exposure suppresses the perinatal testosterone surge.

\section{ER antagonist or androgen coadministration with estrogen mitigates estrogen-induced penile dysmorphogenesis}

Male pups received olive oil (controls), or oil containing DES $(0.1 \mathrm{mg} / \mathrm{kg})$, or DES + DHT $(20 \mathrm{mg} / \mathrm{kg}$, Rivas et al. 2003), or DES + testosterone (20 mg/kg, Rivas et al. 2003), or DES + ICl 182780 (25 mg/kg, Jesmin et al. 2002), or DHT, or testosterone, or ICI 182 780, each day, for 1-6 postnatal days ( $n=7-8$ each group). Penises were collected at 28 days of age and radiographed to determine status of the development of the os penis and measured for their length and weight. ICI, DHT, and testosterone coadministration mitigated DES-induced defects, including reductions in the length and weight of the penis and malformation of the os penis (Fig. 4E and F); although, comparatively, the mitigation was somewhat lower in the case of DES and testosterone. In conclusion, the prevention of estrogen-inducible penile abnormalities by $\mathrm{ICl}$ treatment implies that a functional ER is essential for inducing penile abnormalities. Likewise, the ability of DHT or testosterone to negate these abnormalities, although at a lower level than with $\mathrm{ICl}$, suggests a role for AR-mediated pathway, probably by negating estrogen-induced lower androgen action at the level of penile stromal cells.

\section{Mechanism of estrogen-induced penile dysmorphogenesis}

Results of our studies provided evidence for the first time that estrogen exposure to neonatal male pups induced permanent dysmorphogenesis of the penis characterized by replacement of cavernous spaces and smooth muscle cells by fat cells in the corpora cavernosa penis. Similar novel effects have not been reported in the rat or any other species except the rabbit, where bisphenol A (Moon et al. 2001) or tetrachlorodibenzodioxin (Moon et al. 2004) treatment at puberty resulted in deposition of fat, a reduction in cavernous spaces, and an increase in smooth muscle cells in the corpora cavernosa. Some differences between our studies and those of the latter authors may be attributed to differences in the species (rat versus rabbit), estrogenic compound (DES versus bisphenol A), and/or the time of treatment (neonatal versus pubertal). Nevertheless, these data point to smooth muscle cells and cavernous spaces in the body of the penis as primary targets for estrogen action.

Studies aimed at elucidation of mechanisms through which aberrant estrogen exposure affects restructuring of the corpora cavernosa will provide important insights into mechanisms governing early development of the penis. Based upon observations from other studies (Murakami 1986, 1987) that both smooth muscle cells and cavernous spaces were absent in the rat penis at birth and started to differentiate from stromal cells after 5-6 days of age, we hypothesized that the structural changes that we observed in the corpora cavernosa may have resulted from estrogenic effects limited to the early period of penile development. Indeed, this was confirmed in our developmental study in which rats treated prior to 12 days of age, but not after, developed permanent penile abnormalities and loss of fertility, implying postnatal days $1-12$ as the period when penis was sensitive to estrogen exposure (Goyal et al. 2005b). Additional observations confirmed that the magnitude of these effects (for example, increase in the number, size and percent area of adipocytes) was higher in the 1-6 day group than in the 7-12 day group determined 1-6 postnatal days as the most sensitive period. It is noteworthy here that the rat penis during this estrogensensitive period contains only stromal cells in the corpora cavernosa (lacks smooth muscle cells and cavernous spaces) and thus is similar developmentally to the human penis in the first and second trimesters of pregnancy (Williams-Ashman \& Reddi 1991, George \& Wilson 1994, Klonisch et al. 2004).

Whether the observed effects of estrogen on penile dysmorphogenesis result from an ER-mediated pathway or an AR-mediated pathway, or both ways remains unclear. Support for an ER-mediated pathway comes from observations that both $E R \alpha$ and $\beta$ are present in stromal cells in 1-day-old rat penis (Jesmin et al. 2002, Mowa et al. 2006), estrogens inhibit proliferation of smooth muscle of injured blood vessels (Goyal \& Oparil 2001), and the estrogen metabolite, 2-methoxyestradiol, inhibits angiogenesis (Fotsis et al. 1994). Additionally, $E R \propto$ up-regulation is associated with abnormal development in rodents of the female reproductive tract (Yamashita et al. 1990, Markey et al. 2005), mammary gland (Tekmal et al. 2005), male reproductive tract (Sato et al. 1994), prostate gland (Prins \& Birch 1997, Prins et al. 2001), and seminal vesicles (Williams et al. 2001). In addition, ER $\alpha$ overexpression is shown to inhibit growth and angiogenic factors in the endometrial carcinoma cell line Ishikawa (Ali et al. 2004); and ER $\alpha$ is the main regulator of estrogenic effect on adipose tissue, especially that an alteration in estrogen/ER signaling during development results in dramatic 
changes in adipocyte number (Cooke \& Naaz 2004). Thus, evidence in our studies of association between estrogen-inducible penile abnormalities and enhanced $E R \alpha$ expression, mitigation of estrogen-inducible penile deformities by ER antagonist ICI 182 780, and lack of estrogen-inducible abnormalities in the penis of ER $\alpha K O$ mice indicates that a functional $E R \propto$ pathway is essential in induction of aberrant penile development.

Alternatively, ARs are present throughout the body of the rat penis (Goyal et al. 2004b); AR concentration reaches a peak level at or prior to puberty when stromal cells are differentiating into smooth muscle cells and cavernous spaces (Rajfer et al. 1980, Takane et al. 1990); and neonatal estrogen exposure reduces AR expression in male reproductive organs (Prins \& Birch 1995, McKinnell et al. 2001, Williams et al. 2001, Woodham et al. 2003) and lowers plasma testosterone (Sharpe et al. 1998, Atanassova et al. 2000). Additionally, the coadministration of testosterone with DES prevents most of the histopathological abnormalities affecting the male reproductive tract in rats (Rivas et al. 2003). Low androgen in vitro inhibits smooth muscle differentiation and promotes adipocyte differentiation in pluripotent mesenchymal cells (Bhasin et al. 2003, Singh et al. 2003); and castration induces fat deposition and loss of smooth muscle cells in the corpora cavernosa of the rabbit penis (Traish et al. 2005).

Collectively, the above observations suggest a lower testosterone and/or decreased AR activation as factors contributing indirectly to development of estrogeninducible penile abnormalities. Our observations that coadministration of testosterone or DHT negates estrogen-inducible penile abnormalities and that estrogen exposure for 1-3 postnatal days reduces the perinatal testosterone surge by almost $90 \%$ at postnatal day 5 or 8 (Goyal et al. 2005b), the developmental period when stromal cells start differentiation into smooth muscle cells in the rat penis (Murakami 1986, 1987, provide credence to the indirect effect hypothesis. In other words, the perinatal testosterone surge, typical for rodents from late gestation to first week (Ward \& Weisz 1984, El-Gehani et al. 1998), may be a natural mechanism of dampening $E R \alpha$ expression in stromal cells and, thereby, safeguarding their normal differentiation into smooth muscle cells and endothelial-lined cavernous spaces at a critical period of penile development.

Hence, our working hypothesis of estrogen-inducible abnormal development of the penis in our rat model is as follows (Fig. 5): neonatal estrogen exposure inhibits the perinatal testosterone surge by the fetal Leydig cells; the resulting lower androgen action up-regulates $E R \alpha$ in penile stromal cells; ER $\alpha$ overexpressing stromal cells, when exposed to sufficient estrogen, are reprogrammed toward increased adipogenesis (in other words, a mere ER $\alpha$ overexpression may not be adequate for stromal cell reprogramming).

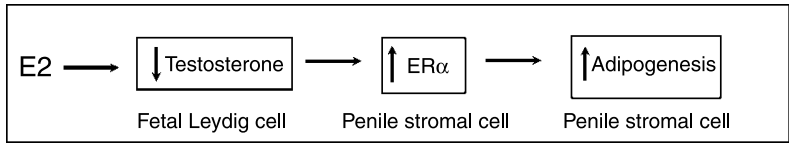

Figure 5 A diagrammatic summary of our hypothesis illustrating how neonatal exposure to estrogen reprograms penile stromal cells such that differentiation into adipocytes is up-regulated.

If this working hypothesis is correct then ICI 182780 coadministration will reverse DES effects by acting both at the Leydig cells and stromal cells (we expect to see high perinatal testosterone surge, low ER $\alpha$ in stromal cells, normal stromal cell differentiation); testosterone coadministration will reverse DES effects by acting primarily at the stromal cells (lower testosterone surge, low ER $\alpha$ in stromal cells, and normal stromal cell differentiation); and antiandrogenic action alone, resulting from gonadotrophinreleasing hormone antagonist $(\mathrm{GnRH}-\mathrm{A})$ and/or flutamide treatments, will up-regulate ER $\alpha$ in stromal cells, but they may or may not be reprogrammed toward increased adipogenesis because of insufficient estrogen exposure.

In summary, we describe a rat model of permanently abnormally developed penis resulting from neonatal DES exposure for a very short period (as short as for 1-3 postnatal days) and at a moderate dose $(0.1 \mathrm{mg} / \mathrm{kg}$ body weight; note this dose is miniscule in comparison to a total median dose of $200 \mathrm{mg} / \mathrm{kg}$ given to a cohort of women at the Boston Lying-in hospital in 1950-1970, Heinonen 1973). Additional experiments using pharmacological approaches (ER antagonist ICI 182 780, AR agonist DHT, centrally acting anti-androgen GnRH-A, and peripherally acting anti-androgen flutamide) are warranted to further understand mechanisms whereby increased ER $\alpha$ activity or lower AR activity or both reprogram stromal cells such that their differentiation into smooth muscle cells is inhibited and their differentiation into adipocytes is stimulated. These findings will be significant because humans and animals are continuously exposed to environmental estrogens (referred to as endocrine disruptors) and anti-androgens (vinclozolin and phthalates) and thus may be more prone to higher incidence of reproductive disorders.

\section{Acknowledgements}

Authors acknowledge the technical help of Ms Salimata KoneCoulibaly in tissue collection, Dr John R Kammermann (Auburn University) in radiographs, and Dr Mahmoud Mansour (Auburn University) in RT-PCR. This research was supported by NIH grants MBRS-5-S06-GM-08091 (to H G) and RCMI-5G12RR03059 and by USDA grant CSR-EES-ALX-TU-CTIF. AII animal procedures were approved by the Tuskegee University Animal Care and Use Committee. The authors declare that there is no conflict of interest that would prejudice the impartiality of this scientific work. 


\section{References}

Ali SH, O'Donnell AL, Mohamed S, Mousa S \& Dandona P 2004 Overexpression of estrogen receptor alpha in the endometrial carcinoma cell line Ishikawa: inhibition of growth and angiogenic factors. Gynecologic Oncology 95 637-645.

Anderson CA \& Clark RL 1990 External genitalia of the rat: normal development and the histogenesis of $5 \alpha$-reductase inhibitor-induced abnormalities. Teratology 42 483-496.

Atanassova N, McKinnell C, Turner KJ, Walker M, Fisher JS, Morley M, Millar MR, Groome NP \& Sharpe RM 2000 Comparative effects of neonatal exposure of male rats to potent and weak (environmental) estrogens on spermatogenesis at puberty and the relationships to adult testis size and fertility: evidence for stimulatory effects of low estrogen levels. Endocrinology 141 3898-3907.

Bhasin S, Taylor WE, Singh R, Artaza J, Sinha-Hikim I, Jasuja R, Choi H \& Gonzalez-Cadavid NF 2003 The mechanisms of androgen effects on body composition: mesenchymal pluripotent cell as the target of androgen action. Journal of Gerontology 58 1103-1110.

Cooke PS \& Naaz A 2004 Role of estrogen in adipocyte development and function. Experimental Biology and Medicine 229 1127-1135.

Crescioli C, Maggi M, Vannelli GB, Ferruzzi P, Granchi S, Mancina R, Muratori M, Forti G, Serio M \& Luconi M 2003 Expression of functional estrogen receptors in human fetal male external genitalia. Journal of Clinical Endocrinology and Metabolism 88 1815-1824.

Dietrich W, Haitel A, Huber JC \& Reiter WJ 2004 Expression of estrogen receptors in human corpus cavernosum and male urethra. Journal of Histochemistry and Cytochemistry 52 355-360.

El-Gehani F, Zhang FP, Pakarinen P, Rannikko A \& Huhtaniemi I 1998 Gonadotropin-independent regulation of steroidogenesis in the fetal rat testis. Biology of Reproduction 58 116-123.

Fisher JS 2004 Environmental anti-androgens and male reproductive health: focus on phthalates and testicular dysgenesis syndrome. Reproduction 127 305-315.

Foster PMD \& Harris MW 2005 Changes in androgen-mediated reproductive development in male rat offspring exposure to a single oral dose of flutamide at different gestational ages. Toxicological Sciences 85 1024-1032.

Fotsis T, Zhang Y, Pepper MS, Adlercreutz H, Montesano R, Nawroth PP \& Schweigerer L 1994 The endogenous oestrogen metabolite 2-methoxyoestradiol inhibits angiogenesis and suppresses tumor growth. Nature 368 237-239.

George FW \& Wilson JD 1994 Sex determination and differentiation. In The Physiology of Reproduction, pp 3-28. Eds E Knobil \& J Neil. New York: Raven Press.

Gill WB, Schumacher GFB, Bibbo M, Straus FH \& Schoenberg HW 1979 Association of diethylstilbestrol exposure in utero with cryptorchidism, testicular hypoplasia and semen abnormalities. Journal of Urology 122 36-39.

Goyal MK \& Oparil S 2001 Direct estrogen effects on the cardiovascular system. In Contemporary Endocrinology: Selective Estrogen Receptor Modulators: Research and Clinical Applications, pp 99-119. Eds A Manni \& MF Verderame. Totowa, NJ: Humana Press.

Goyal HO, Braden TD, Williams CS, Dalvi P, Williams JW \& Srivastava KK 2004a Exposure of neonatal male rats to estrogen induces abnormal morphology of the penis and loss of fertility. Reproductive Toxicology 18 265-274.

Goyal HO, Braden TD, Williams CS, Dalvi P, Mansour MM, Mansour M, Williams JW, Bartol FF, Wiley AA, Birch L et al. 2004b Abnormal morphology of the penis in male rats exposed neonatally to diethylstilbestrol is associated with altered profile of estrogen receptor- $\alpha$ protein, but not of androgen receptor protein: A developmental and immunocytochemical study. Biology of Reproduction 70 284-297.

Goyal HO, Braden TD, Williams CS, Dalvi P, Mansour MM \& Williams JW 2005a Permanent induction of morphological abnormalities in the penis and penile skeletal muscles in adult rats treated neonatally with diethylstilbestrol or estradiol valerate: A dose-response study. Journal of Andrology 26 32-43.

Goyal HO, Braden TD, Williams CS, Dalvi P, Mansour M \& Williams JW 2005b Estrogen-induced abnormal accumulation of fat cells in the rat penis and associated loss of fertility depends upon estrogen exposure during critical period of penile development. Toxicological Sciences 87 242-254.

Goyal HO, Braden TD, Cooke PS, Szewczykowski MA, Williams CS, Dalvi P \& Williams JW 2007 Estrogen receptor- $\alpha$ mediates estrogeninducible abnormalities in the developing penis. Reproduction 133 1057-1067.

Gray LE Jr, Ostby J, Furr J, Wolf CJ, Lambright C, Parks L, Veeramachaneni DN, Wilson V, Price M, Hotchkiss A et al. 2001 Effects of environmental antiandrogens on reproductive development in experimental animals. Human Reproduction Update 7 248-264.

Gupta C 2000 Reproductive malformation of the male offspring following maternal exposure to estrogenic chemicals. Proceedings of the Society of Experimental Biology and Medicine 224 61-68.

Heinonen OP 1973 Diethylstilbestrol in pregnancy. Frequency of exposure and usage patterns. Cancer 31 573-577.

Jesmin S, Mowa CN, Matsuda N, Salah-Eldin A-E, Togashi H, Sakuma I, Hattori Y \& Kitabatake A 2002 Evidence for a potential role of estrogen in the penis: detection of estrogen receptor- $\alpha$ and $-\beta$ messenger ribonucleic acid and protein. Endocrinology 143 4764-4774.

Jesmin S, Mowa CN, Sakuma I, Matsuda N, Togashi H, Yoshioka M, Hattori Y \& Kitabatake A 2004 Aromatase is abundantly expressed by neonatal rat penis but downregulated in adulthood. Journal of Molecular Endocrinology 33 343-359.

Kim KS, Liu W, Cunha GR, Russell DW, Huang H, Shapiro E \& Baskin LS 2002 Expression of the androgen receptor and 5 alphareductase type 2 in the developing human fetal penis and urethra. Cell and Tissue Research 307 145-153.

Kim KS, Torres CR Jr, Yucel S, Raimondo K, Cunha GR \& Baskin LS 2004 Induction of hypospadias in a murine model by maternal exposure to synthetic estrogens. Environmental Research 94 267-275.

Klip H, Verloop J, van Gool JD, Koster ME, Burger CW \& van Leeuwen FE 2002 Hypospadias in sons of women exposed to diethylstilbestrol in utero: a cohort study. Lancet 359 1081-1082.

Klonisch T, Fowler PA \& Hombach-Klonisch S 2004 Molecular and genetic regulation of testis descent and external genitalia development. Developmental Biology 270 1-18.

Markey CM, Wadia PR, Rubin BS, Sonnenschein C \& Soto AM 2005 Long-term effects of fetal exposure to low doses of the xenoestrogen bisphenol-A in the female mouse genital tract. Biology of Reproduction 72 1344-1351.

McKinnell C, Atanassova N, Williams K, Fisher JS, Walker M, Turner KJ, Saunders PTK \& Sharpe RM 2001 Suppression of androgen action and the induction of gross abnormalities of the reproductive tract in male rats treated neonatally with diethylstilbestrol. Journal of Andrology 22 323-338.

McLachlan JA, Newbold RR \& Bullock B 1975 Reproductive tract lesions in male mice exposed prenatally to diethylstilbestrol. Science 190 991-992.

McLachlan JA, Newbold RR, Burow ME \& Li SF 2001 From malformations to molecular mechanisms in the male: three decades of research on endocrine disrupters. Acta Pathologica, Microbiologica, et Immunologica Scandinavica 109 263-272.

Moon DG, Sung DJ, Kim YS, Cheon J \& Kim JJ 2001 Bisphenol A inhibits penile erection via alteration of histology in the rabbit. International Journal of Impotence Research 13 309-316.

Moon DG, Lee KC, Kim YW, Park HS, Cho HY \& Kim JJ 2004 Effect of TCDD on corpus cavernosum histology and smooth muscle physiology. International Journal of Impotence Research $\mathbf{1 6}$ 224-230. 
Mosconi G, Carnevali O, Franzoni MF, Cottone E, Lutz I, Kloas W, Yamamoto K, Kikuyama S \& Polzonetti-Magni AM 2002 Environmental estrogens and reproductive biology in amphibians. General and Comparative Endocrinology 126 125-129.

Mowa CN, Jesmin S \& Miyauchi T 2006 The penis: a new target and source of estrogen in male reproduction. Histology and Histopathology 21 53-67.

Murakami R 1986 Development of the os penis in genital tubercles cultured beneath the renal capsule of adult rats. Journal of Anatomy 149 11-20.

Murakami RA 1987 Histological study of the development of the penis of wild-type and androgen-insensitive mice. Journal of Anatomy 153 223-231.

Newbold RR 2004 Lessons learned from perinatal exposure to diethylstilbestrol. Toxicology and Applied Pharmacology 199 142-150.

Prins GS \& Birch L 1995 The developmental pattern of androgen receptor expression in rat prostate lobes is altered after neonatal exposure to estrogen. Endocrinology 136 1303-1314.

Prins GS \& Birch L 1997 Neonatal estrogen exposure up-regulates estrogen receptor expression in the developing and adult rat prostate lobes. Endocrinology 138 1801-1809.

Prins GS, Birch L, Couse JF, Choi I, Katzenellenbogen B \& Korach KS 2001 Estrogen imprinting of the developing prostate gland is mediated through stromal estrogen receptor : studies with $\alpha \mathrm{ERKO}$ and $\beta E R K O$ mice. Cancer Research 61 6089-6097.

Putz O, Schwartz CB, LeBlanc GA, Cooper RL \& Prins GS 2001 Neonatal low- and high-dose exposure to estradiol benzoate in the male rat: II. Effects on male puberty and the male reproductive tract. Biology of Reproduction 65 1506-1517.

Rajfer J, Namkung PC \& Petra PH 1980 Identification, partial characterization and age-related changes of a cytoplasmic androgen receptor in the rat penis. Journal of Steroid Biochemistry 13 1489-1492.

Rivas A, McKinnell C, Fisher JS, Atanassova N, Williams K \& Sharpe RM 2003 Neonatal coadministration of testosterone with diethylstilbestrol prevents induction of most reproductive tract abnormalities in male rats. Journal of Andrology 24 557-567.

vom Saal FS \& Hughes C 2005 An extensive new literature concerning low-dose effects of bisphenol A shows the need for new risk assessment. Environmental Health Perspectives 113 926-933.

vom Saal FS, Timms BG, Montano MM, Palanza P, Thayer KA, Nagel SC, Dhar MD, Ganjam VK, Parmigiani S \& Welshons WV 1997 Prostate enlargement in mice due to fetal exposure to low doses of estradiol or diethylstilbestrol and opposite effects at high doses. PNAS 94 2056-2061.

Safe SH, Pallaroni L, Yoon K, Gaido K, Ross S, Saville B \& McDonnell D 2001 Toxicology of environmental estrogens. Reproduction, Fertility, and Development 13 307-315.

Sato T, Chiba A, Hayashi S, Okamura H, Okamura H, Ohta Y, Takasugi N \& Iguchi T 1994 Induction of estrogen receptor and cell division in genital tracts of male mice by neonatal exposure to diethylstilbestrol. Reproductive Toxicology 8 145-153.

Schultheiss D, Badalyan R, Pilatz A, Gabouev AI, Schlote N, Wefer J, von Wasielewski R, Mertsching H, Sohn M, Stief CG et al. 2003 Androgen and estrogen receptors in the human corpus cavernosum penis: immunohistochemical and cell culture results. World Journal of Urology 21 320-324.

Sharpe RM, Atanassova N, McKinnell C, Parte P, Turner KJ, Fisher JS, Kerr JB, Groome NP, Macpherson S, Millar MR et al. 1998 Abnormalities in functional development of Sertoli cell in rats treated neonatally with diethylstilbestrol: a possible role for estrogens in Sertoli cell development. Biology of Reproduction $\mathbf{5 9}$ 1084-1094.
Singh R, Artaza JN, Taylor WE, Gonzalez-Cadavid NF \& Bhasin S 2003 Androgens stimulate myogenic differentiation and inhibit adipogenesis in C3H 10T1/2 pluripotent cells through an androgen receptormediated pathway. Endocrinology 144 5081-5088.

Srilatha B \& Adaikan PG 2004 Estrogen and phytoestrogen predispose to erectile dysfunction: Do ER- $\alpha$ and ER- $\beta$ in the cavernosum play a role? Urology 63 382-386.

Storgaard L, Bonde JP \& Olsen J 2006 Male reproductive disorders in humans and perinatal indicators of estrogen exposure. A review of published epidemiological studies. Reproductive Toxicology 21 4-15.

Sultan C, Paris F, Terouanne B, Balaguer P, Georget V, Poujol N, Jeandel C, Lumbroso S \& Nicolas J-C 2001 Disorders linked to insufficient androgen action in male children. Human Reproduction Update 7 314-322.

Swan SH 2000 Intrauterine exposure to diethylstilbestrol: long-term effects in humans. Acta Pathologica, Microbiologica, et Immunologica Scandinavica 108 793-804.

Takane KK, George FW \& Wilson JD 1990 Androgen receptor of rat penis is down regulated by androgen. American Journal of Physiology 21 E46-E50.

Tekmal RR, Liu Y-G, Nair HB, Jones J, Perla RP, Lubahn DB, Korach KS \& Kirma N 2005 Estrogen receptor alpha is required for mammary development and the induction of mammary hyperplasia and epigenetic alterations in the aromatase transgenic mice. Journal of Steroid Biochemistry and Molecular Biology 95 9-15.

Toppari J, Larsen JC, Christiansen P, Giwercman A, Grandjean P, Guillette LJ Jr, Jegou B, Jensen TK, Jouannet P, Keiding N et al. 1996 Male reproductive health and environmental xenoestrogens. Environmental Health Perspectives 104 741-803.

Traish AM, Toselli P, Jeong SJ \& Kim NN 2005 Adipocyte accumulation in penile corpus cavernosum of the orchiectomized rabbit: A potential mechanism for veno-occlusive dysfunction in androgen deficiency. Journal of Andrology 26 242-248.

Vidaeff AC \& Sever LE 2005 In utero exposure to environmental estrogens and male reproductive health: a systematic review of biological and epidemiologic evidence. Reproductive Toxicology 20 5-20.

Ward IL \& Weisz J 1984 Differential effects of maternal stress on circulating levels of corticosterone, progesterone, and testosterone in male and female rat fetuses and their mothers. Endocrinology 114 1635-1644.

Williams K, Fisher JS, Turner KJ, McKinnell C, Saunders PTK \& Sharpe RM 2001 Relationship between expression of sex steroid receptors and structure of the seminal vesicles after neonatal treatment of rats with potent or weak estrogens. Environmental Health Perspectives 109 21-29.

Williams-Ashman HG \& Reddi AH 1991 Differentiation of mesenchymal tissues during phallic morphogenesis with emphasis on the os penis: Roles of androgens and other regulatory agents. Journal of Steroid Biochemistry and Molecular Biology 39 873-881.

Wilson CA \& Davies DC 2007 The control of sexual differentiation of the reproductive system and brain. Reproduction 133 331-359.

Woodham C, Birch L \& Prins GS 2003 Neonatal estrogen downregulates prostatic androgen receptor through a proteosomemediated protein degradation pathway. Endocrinology 144 4841-4850.

Yamashita S, Newbold RR, McLachlan JA \& Korach KS 1990 The role of the estrogen receptor in uterine epithelial proliferation and cytodifferentiation in neonatal mice. Endocrinology 127 2456-2463.

Received 7 May 2007

First decision 12 June 2007

Accepted 20 June 2007 